\title{
A reforma do Ensino Superior no campo da formação dos profissionais da educação básica: As políticas educacionais e o movimento dos educadores
}

\author{
Helena Costa Lopes de Freitas*
}

\begin{abstract}
RESUMO: O presente trabalho apresenta as discussões que têm orientado o debate acerca da formação dos profissionais da educação, recuperando a trajetória do movimento dos educadores na luta pela sua formação e pela profissionalização do magistério - representada na atualidade pela Associação Nacional pela Formação dos Profissionais da Educação (Anfope) - nos últimos 20 anos. A construção coletiva em torno da base comum nacional, em oposição às políticas de formação, e a proposta de escola única de formação, que materializa os princípios da Anfope para a reorganização dos cursos de formação dos profissionais da educação nas universidades, vêm orientando o debate atual na resistência às políticas oficiais de aligeiramento e fragmentação da formação profissional.
\end{abstract}

Palavras-chave: Formação de professores, base comum nacional, profissionais da educação, políticas de formação

\section{Introdução}

As reformas educativas levadas a efeito em nosso país e nos outros países da América Latina desde o final da década de 1970, com o objetivo de adequar o sistema educacional ao processo de reestruturação produtiva e aos novos rumos do Estado, vêm reafirmando a centralidade da formação dos profissionais da educação. Nesse contexto, debatem-se di-

\footnotetext{
* Professora da Faculdade de Educação, Unicamp e presidente da Associação Nacional pela Formação dos Profissionais da Educação (Anfope). Email: helena@obelix.unicamp.br
} 
ferentes propostas para a formação, fundadas em projetos políticos e perspectivas históricas diferenciadas, o que faz com que a formação desses profissionais seja tratada ou como elemento impulsionador e realizador dessas reformas, ou como elemento que cria condições para a transformação da própria escola, da educação e da sociedade.

No quadro das políticas educacionais neoliberais e das reformas educativas, a educação constitui-se em elemento facilitador importante dos processos de acumulação capitalista e, em decorrência, a formação de professores ganha importância estratégica para a realização dessas reformas no âmbito da escola e da educação básica (Aguiar 1997, Freitas 1994, 1995).

A importância dada à questão da formação pelas políticas atuais tem por objetivo equacionar o problema da formação para elevar os níveis de "qualidade" da educação nos países subdesenvolvidos, qualidade que, na concepção do Banco Mundial, é determinada por vários fatores, entre os quais situam-se o tempo de instrução, os livros didáticos e a melhoria do conhecimento dos professores (privilegiando a capacitação em serviço sobre a formação inicial e estimulando as modalidades a distância). À formação geral, garantida no Ensino Médio a baixo custo, seria agregada a formação para a docência, oferecida em cursos curtos de formação inicial centrados na capacitação pedagógica (Torres 1996, p. 165).

Em nosso país, a implementação dessas concepções via políticas de formação vem se dando desde o final dos anos 80 e se consolida na década de 1990, em decorrência dos acordos firmados na histórica Conferência de Ministros da Educação e de Planejamento Econômico, realizada no México, em 1979, e na Conferência de Jontien, em 1990, na Tailândia. Várias iniciativas foram tomadas, em especial na América Latina e no Caribe, como tentativa de responder à crise de acumulação do capitalismo, no sentido de "elevar o nível de satisfação das necessidades básicas de aprendizagem", pilar do plano de ação Educação Para Todos que fundamentou, em nosso país, o Plano Decenal. A "qualidade" da educação e da escola básica passa a fazer parte das agendas de discussões e do discurso de amplos setores da sociedade, e das ações e políticas do MEC, que busca a cooptação para criar consensos facilitadores das mudanças necessárias na escola básica e, principalmente, no campo da formação de professores (Freitas 1994).

As concepções que orientam tais mudanças vêm sendo questionadas ao serem confrontadas com a produção teórica e prática da área educacional e do movimento dos educadores que, desde o final dos anos 
70 , com o processo de democratização da sociedade, passa a colocar novas exigências para a melhoria da escola básica e para a formação de professores. A Associação Nacional pela Formação dos Profissionais da Educação (Anfope) - que se organiza a partir de 1983 como Comissão Nacional pela Formação dos Profissionais da Educação (Conarcfe) -, no movimento de reformulação dos cursos de formação do educador, vem contribuindo com essa discussão, construindo coletivamente uma concepção sócio-histórica de educador em contraposição ao caráter tecnicista e conteudista que tem caracterizado as políticas de formação de professores para a escola básica em nosso país. Ela tem, na concepção de base comum nacional, em oposição à concepção de currículo mínimo, o instrumento que marca a resistência às políticas de aligeiramento, fragilização e degradação da formação e da profissão do magistério.

Faz parte também dessa trajetória na luta pela formação a definição de uma política nacional global de formação dos profissionais da educação e valorização do magistério, que contemple de forma prioritária no quadro das políticas educacionais, e em condições de igualdade, a sólida formação inicial no campo da educação, condições de trabalho, salário e carreira dignas e a formação continuada como um direito dos professores e obrigação do Estado e das instituições contratantes.

Este trabalho analisa, em um primeiro momento, as reformas no campo da formação de professores a partir da LDB 9.394/96, a Lei de Diretrizes e Bases da Educação Nacional, destacando a posição da Anfope e do movimento dos educadores em relação a elas. Em seguida, são retomados os pontos principais da política nacional de formação dos profissionais da educação, enfatizando as condições da formação inicial a base comum nacional e a intervenção no processo de discussão das diretrizes curriculares para os cursos de formação. Por último, é discutida a proposta de escola única de formação, uma alternativa de reorganização e estruturação dos cursos de formação de profissionais da educação no interior das faculdades e dos centros de educação e das universidades.

\section{As políticas atuais para a formação dos profissionais da educação}

A aprovação da nova LDB, em dezembro de 1996, representou o marco da institucionalização de políticas educacionais que já vinham sendo gestadas e implantadas pelo $\mathrm{MEC}^{1}$ e pelo governo anterior. As 
medidas no campo da formação, regulamentadas pelo CNE, têm se caracterizado por aprovações pontuais de pareceres e resoluções que vão conformando a reforma universitária no campo da formação. Destacamse a Resolução 02/97 (antigos Esquema I e II, agora revigorados), que estabelece a possibilidade de complementação pedagógica para qualquer graduado/bacharel que queira atuar na educação básica; a regulamentação do curso normal em nível médio, sem que tenha sido definido o caráter transitório e datado dessa instância de formação bem como a política de formação em nível superior dos estudantes que finalizam esse curso; a regulamentação dos cursos seqüenciais que oferecem diploma e concorrem com os tradicionais cursos de graduação, abrindo a possibilidade de retomada das antigas licenciaturas curtas de 1.600 horas.

No quadro dessas políticas, destaca-se ainda a elaboração das Diretrizes Curriculares para a graduação, que fincará as bases para a organização curricular dos cursos de formação dos profissionais da educação.

A LDB instituiu também as bases para a definição de novas políticas que vêm sendo regulamentadas pelo Conselho Nacional de Educação, com a criação de novas instituições: os Institutos Superiores de Educação, instituição específica para formação de professores para a educação básica, o Curso Normal Superior, para formação de professores de $1^{1}$ a $4^{a}$ série e educação infantil, e a formação dos especialistas nos cursos de pedagogia.

Posteriormente, o Decreto 2.032 de agosto de 1997, que alterou o sistema federal de Ensino Superior e a organização acadêmica das IES, regulamenta essa nova instituição e seu lugar no "concerto" do Ensino Superior brasileiro. O decreto estabelece que as Instituições de Ensino Superior podem assumir diferentes formatos: universidades, centros universitários, faculdades integradas, faculdades e institutos superiores ou escolas superiores. Com essas distinções, e mantendo-se a exigência da pesquisa apenas nas universidades, institucionaliza-se a distinção entre universidades de ensino e universidades de pesquisa, mantida no Plano Nacional de Educação elaborado pelo relator da Comissão de Educação e Cultura, reservando para os Institutos Superiores de Educação, uma instituição de quinta categoria, segundo a própria hierarquização formulada pelo MEC para as IES, a formação dos quadros do magistério.

A recente regulamentação dos Institutos Superiores de Educação, pelo Parecer no 115/99 da Câmara de Ensino Superior do CNE, deixa clara a concepção de formação de professores que permeia as propostas 
atuais, ao estabelecer que a preparação dos profissionais para atuar na educação básica se dará fundamentalmente em uma instituição de ensino de caráter técnico-profissional.

As implicações dessa forma de organização do Ensino Superior para a formação dos profissionais da educação têm sido anunciadas e denunciadas tanto pelas diferentes entidades acadêmicas - Anfope, Anped, Anpae, Fórum de Diretores das Faculdades de Educação das Universidades Públicas Brasileiras - quanto por estudiosos da área (Aguiar 1997, Anfope 1998, 1999, Kuenzer 1998).

Para efeito de análise, retomamos aqui algumas dessas questões, centrando a discussão nas condições de formação, buscando identificar seus fundamentos no quadro atual. No campo das possibilidades da organização curricular e dos estudos a serem oferecidos, pode-se identificar uma situação discriminatória em relação aos demais cursos de graduação. Senão vejamos.

É um curso de caráter técnico-profissionalizante. A carga horária para integralização do curso - 3.200 horas - pode ser reduzida, dependendo da experiência e da formação anterior dos estudantes, podendo chegar até a 1.600 horas. Com isso, constata-se que, pela primeira vez, se abre a possibilidade de aproveitamento, em nível superior, dos estudos realizados em nível anterior de escolaridade, desqualificando e banalizando o rigor necessário que deveria ser exigido dos estudos superiores.

Outra característica discriminatória é a exigência de qualificação do corpo docente $-10 \%$ de mestres e doutores -, que contrasta com a exigência de qualificação nas universidades - 30\% de mestres e doutores -, caracterizando uma desqualificação dos formadores de professores, com sérias implicações no ensino e nos estudos desenvolvidos nessas instituições.

As diretrizes curriculares que orientarão a elaboração dos currículos e os estudos tomarão por base as diretrizes para a educação básica, ao contrário do processo que tem orientado a elaboração das diretrizes para os cursos de graduação, que toma como parâmetros e princípios orientadores os conhecimentos científicos da área de formação. Essa forma de organização nos leva a afirmar que os estudos que aí se desenvolverão, separados da pesquisa e da produção de conhecimento nas áreas de formação - tanto nas disciplinas de conteúdo das áreas específicas da docência quanto na área educacional -, adquirirão caráter técnico e instrumental, retirando do profissional da educação a pos- 
sibilidade de desenvolver-se como "intelectual responsável por uma área específica do conhecimento, atribuindo-se a ele uma dimensão tarefeira, para o que não precisa se apropriar dos conteúdos da ciência e da pesquisa pedagógica" (Kuenzer apud Aguiar 1999).

Tais características apontam para a constituição de uma instituição formadora de caráter pós-médio, e não superior. Assim, em vez de se buscar o que há de mais avançado em termos de propostas de organização curricular e experiências em curso nas IES, em particular nos cursos de pedagogia, coloca-se como horizonte o aligeiramento da formação pelo rebaixamento das exigências e das condições de formação.

Esse rebaixamento das exigências em vários níveis - corpo docente, carga horária -, aliado às pressões dos sistemas de ensino estaduais e municipais para a qualificação de seus docentes até 2007, em cumprimento à LDB e na ausência de política de expansão qualificada do Ensino Superior público, que demandaria maior volume de recursos financeiros, tem causado a proliferação de cursos de 1.600 horas e a criação de numerosas instituições privadas que se beneficiam dessas condições "ideais" para seu crescimento e expansão, nem sempre com a qualidade necessária.

É contra essa política que a Anfope tem se posicionado, mais especificamente contra o caráter da formação que essas instituições têm possibilidade de oferecer, em decorrência de sua organização. Desde o IV Encontro Nacional, de $1989^{2}$, quando do processo de elaboração da LDB e, posteriormente, em 1994, durante o VII Encontro Nacional, a Anfope vem se posicionando contrariamente a essas iniciativas que já começavam a se configurar como alternativas para a organização dos cursos de formação de professores, pois indicavam "uma reformulação às avessas, desconsiderando as atuais instituições formadoras como locus de produção do conhecimento e agências responsáveis pela formação de profissionais da educação"

Ao contrário do que afirmam alguns autores (Libâneo e Pimenta 1999), a Anfope tem assumido historicamente uma posição contrária a qualquer proposta que vise criar centros específicos de formação de professores, separados dos centros e dos cursos que formam os profissionais da educação e pretendam separar a formação de professores da formação dos demais profissionais da educação e do ensino, ou dos especialistas.

Tal posição tem se mantido historicamente e tem fundamentado as posições da entidade nos diversos fóruns em que é discutida a criação dos Institutos Superiores de Educação, como lugar específico da forma- 
ção exclusiva de professores, separado da universidade. Essa posição foi reafirmada no processo de elaboração do Plano Nacional de Educação da sociedade brasileira (1997), e nos quatro seminários nacionais realizados de 1996 a 1999, promovidos conjuntamente pela Anfope e pelo Fórum de Diretores das Faculdades/Centros de Educação das Universidades Brasileiras. ${ }^{4}$

Nos diferentes documentos, a Anfope tem se posicionado a respeito dessa temática, em particular reiterando a denúncia de que

A proposta mantém as dicotomias e as fragmentações na formação de profissionais da educação quando se dedica, em sua formulação, à formação de professores e não de educadores, enfatizando exclusivamente o conteúdo específico, as metodologias e o projeto pedagógico da escola, reforçando, portanto, a concepção conteudista, tecnicista do professor, reduzindo-o a um prático com pleno domínio da solução de problemas da prática cotidiana da escola e da sala de aula, alijado da investigação e da pesquisa sobre as condições concretas que geram esses problemas. (Anfope 1999)

É exatamente nesse campo que hoje se trava o debate nacional sobre a formação dos profissionais da educação, suas concepções, seu conteúdo e forma, que vai dando lugar a regulamentações, propostas, documentos e formulações oficiais.

A criação de novos cursos e instituições - como os Institutos Superiores de Educação e o Curso Normal Superior ${ }^{5}$ - específicos para a formação de professores é parte da estratégia adotada pelo governo brasileiro, em cumprimento às exigências dos organismos internacionais, para o que seria a segunda etapa da reforma educacional: a reforma no campo da formação de professores. Essa segunda etapa cumpre dois objetivos básicos:

a) adequar as instituições formadoras e os conteúdos da formação aos objetivos da reforma da educação básica em curso, garantindo a aplicação dos princípios da reforma na sala de aula e na escola;

b) para cumprir com eficiência esse objetivo, não é necessário nem desejável que a formação ocorra nas universidades e nos centros em que a produção de conhecimento é parte integrante da formação profissional; é preciso, portanto, separar a formação de professores da 
formação dos demais profissionais da educação e da pós-graduação acadêmica. No caso do Brasil, é preciso separar a formação de professores do curso de pedagogia, reservando-o como um curso de excelência para formar profissionais da educação qualificados no campo da produção de conhecimento. Com essa política, desarticulamse as faculdades e os centros de educação como instituições formadoras de educadores, profissionais de caráter amplo para atuar na docência, instituições que vêm se constituindo como centros produtores de conhecimento, geradores de novas idéias que contestam e fazem a crítica da educação, da escola e do ensino e das políticas moldadas pelas diferentes reformas educacionais.

Mello (1999), ao definir elementos da política para formação inicial de professores, deixa explícito que "é preciso dar prioridade à formação de professores na perspectiva e no âmbito da política de educação básica, independentemente da problemática do ensino superior como tal (...)" . Afirma que seria

inviável para o poder público financiar a preços das universidades "nobres" a formação de seus professores de educação básica que se contam em mais de milhão. Com um volume de recursos muito menor, um sistema misto de custo baixos tanto públicos quanto privados, configura um ponto estratégico de intervenção para promover melhorias sustentáveis a longo prazo na escolaridade básica. (Idem, p. 8; grifos nossos)

Esse documento explicita alguns parâmetros orientadores das políticas do Banco Mundial para a educação básica (Torres 1996) e também as medidas e as políticas governamentais no campo da formação de professores, nos próximos anos, dentre os quais se destacam:

a) Aprofundamento do processo de "ajuste" estrutural, enxugamento dos recursos do Estado para a educação e conseqüente privatização;

b) distribuição, centralização e focalização dos recursos para experiências que se adeqüem aos princípios da reforma educativa em curso;

c) a massificação ${ }^{7}$ e 0 caráter de capacitação pedagógica (pragmatismo e o retorno ao tecnicismo) na formação de professores, 
- $\quad$ ênfase na capacitação pedagógica de professores feita em instituições específicas, exclusivas, sem história e orientadas pelos parâmetros da reforma educativa em curso que necessita "aterrissar na sala de aula";

- rebaixamento das exigências de qualificação do corpo docente das instituições formadoras de professores;

- $\quad$ retirada da formação de professores das faculdades de educação (curso de pedagogia) e das universidades, desarticulando-as como centros de formação de professores, com propostas orientadas por parâmetros acadêmicos e científicos no campo da pesquisa e da formação de profissionais com amplo domínio do conhecimento crítico sobre a educação e a sociedade, em condições de elaborar propostas alternativas às propostas oficiais atuais;

- $\quad$ diretrizes curriculares para a formação fundadas nas diretrizes curriculares para a educação básica e educação infantil, e não em diretrizes curriculares de caráter acadêmico, tal como para os cursos de graduação nas IES; é preconizada uma "sintonia fina" entre as agências formadoras e a reforma educativa.

d) o individualismo e a responsabilidade pessoal no processo formativo:

- desenvolvimento profissional: situa a responsabilidade pela formação continuada no próprio professor, que deve autogerir sua formação continuada, seu desenvolvimento profissional, em contraposição a uma concepção de formação continuada como direito do profissional e dever do Estado e demais instituições contratantes;

- $\quad$ certificação de competências: um novo conceito que orienta a formação profissional - não há direito ao trabalho garantido pelo curso de formação. O exercício do magistério fica condicionado à conclusão de curso em instituição credenciada e à avaliação para certificação de competências docentes;

- avaliação dos professores vinculada à avaliação de desempenho dos alunos no Saeb ou outras formas, para ascensão na carreira.

$\mathrm{Na}$ questão específica da formação de professores para educação infantil e séries iniciais, a situação criada pela LDB é ainda mais comple- 
xa e reacende algumas das polêmicas discussões da década de 1970, ao estabelecer permanência da formação desses professores em nível médio, ao criar o Curso Normal Superior em substituição ao curso de pedagogia e localizar a formação dos especialistas no curso de pedagogia, separada da formação de professores - no Curso Normal Superior.

Não é demais reafirmar que o curso de pedagogia, em grande parte das IES, desde meados da década de 1980, constituiu-se como um curso de graduação plena, licenciatura e bacharelado, com projeto pedagógico próprio, responsável pela formação de profissionais para a educação básica, eliminando a fragmentação das antigas habilitações, e possibilitando sua inserção em outros campos profissionais. É, hoje, o único curso de formação de profissionais da educação que tem essa organização, com projeto pedagógico específico, sob total responsabilidade das faculdades/centros de educação, superando as dicotomias entre bacharelado e licenciatura, formação pedagógica e formação específica, presentes nos demais cursos de licenciatura.

O CNE, ao regulamentar os Institutos Superiores de Educação, ignorou essa trajetória e regulamentou a formação de professores de educação infantil e de $1^{\mathrm{a}}$ a $4^{\mathrm{a}}$ série no Curso Normal Superior, criando o clima propício para que, posteriormente, fosse regulamentada a formação de professores para esses níveis de ensino exclusivamente no Curso Normal Superior, tal como estabelece o Parecer 970/99, da Câmara de Educação Superior, aprovado em 10/11/1999, com apenas sete (dos doze) conselheiros presentes e um voto em contrário, declarado em separado pelo conselheiro Jacques Velloso. Sua aprovação foi antecedida de muita mobilização em nível nacional, de amplos setores da área educacional. Centenas de instituições, entidades, conselhos de cursos e educadores enviaram manifestação ao Conselho Nacional, entre a reunião de outubro e a reunião de novembro do CNE, rejeitando o parecer e solicitando audiência pública para o trato dessa questão. A constatação de que não foi introduzida qualquer modificação na minuta originalmente apresentada à Câmara de Ensino Superior e a insensibilidade diante das centenas de manifestações de todo o país são dados reveladores da força dos interesses que orientam a definição das políticas educacionais em nosso país e das concepções que informam as propostas de formação de professores.

O conteúdo do Parecer 970/99, por outro lado, opõe-se frontalmente aos estudos desenvolvidos pela Comissão de Especialistas de Pedagogia, que, ao definir as diretrizes curriculares para o curso, estabelece a 
docência como base da identidade profissional de todo educador. Essa oposição a uma construção coletiva e histórica no campo da formação de professores demonstra que as decisões no campo da formação vêm respondendo aos interesses de determinados setores, tanto no CNE quanto no MEC, que pretendem colocar os cursos de formação de professores como responsabilidade apenas dos Institutos Superiores de Educação, afastados dos bacharelados e, no que tange à formação de professores para as séries iniciais e a educação infantil, afastada da formação dos demais profissionais do ensino no curso de pedagogia - que se transformaria em um bacharelado (ou pedagogia stricto sensu, uma nova formulação), retirando, portanto, desses cursos e das faculdades de educação a responsabilidade pela formação dos profissionais da educação (Anfope 1999) ${ }^{8}$.

Ao estabelecer que o curso de pedagogia formará os especialistas separadamente da docência, retomando as já superadas habilitações, a regulamentação do CNE contraria o movimento real ${ }^{9}$, a produção teórica na área ${ }^{10}$ e a própria LDB, que estabelece, em seu artigo 67, a experiência docente como pré-requisito para o exercício das demais funções do magistério.

Com isso, retorna agora, em um patamar mais elaborado ${ }^{11}$, a figura do pedagogo "especialista", em oposição à concepção de profissional da educação, educador de caráter amplo que tem na docência, no trabaIho pedagógico, a base de sua formação e de sua identidade profissional. Essa concepção de pedagogo stricto sensu, superada tanto pela produção teórica da área quanto pela prática democrática da organização do trabalho pedagógico nas escolas públicas, articula-se à concepção de professor "tarefeiro", formado com ênfase nos conteúdos específicos.

Essa concepção favorece as políticas governamentais que apontam para uma formação diferenciada entre professores e demais profissionais da educação, e ainda dá espaço para a formação de profissionais para funções de gestão do sistema educacional descoladas do âmbito escolar, numa perspectiva hierarquizada. Nas circunstâncias atuais da escola básica, esse profissional é ressignificado pelo Estado, talvez como um profissional a seu serviço na escola e nos sistemas de ensino para que, diante de professores formados em bases tecnicistas e pragmatistas, possa atuar firme e decisivamente no sentido de fazer cumprir as metas da reforma e das políticas educacionais que a embasam.

O fato de o curso de pedagogia constituir-se sob total e exclusiva responsabilidade das faculdades/centros de educação tem permitido seu 
aprimoramento e aperfeiçoamento na direção de tomar a prática educativa e a educação como objeto de estudo na formação de profissionais para atuação na educação básica - na formação de crianças de 0 a 10 anos -, identificando, no trabalho pedagógico escolar e não-escolar, elementos constitutivos da formação humana em sua dimensão omnilateral ${ }^{12}$.

É essa especificidade que devemos garantir para o curso de pedagogia, cuja "crise" somente se aprofundará com a separação da formação de professores, a retomada das habilitações e a fragmentação na formação dos especialistas.

O que está em jogo, hoje, para o conjunto dos educadores e para a sociedade brasileira é a defesa do campo educacional e, nele, do curso de pedagogia e das faculdades/centros de educação, como espaços de formação do profissional da educação básica estudioso da educação, em condições de exercer sua prática em ambientes formais e não-formais, escolares e não-escolares, e em todos os espaços em que se desenvolva o trabalho educativo.

Sintetizando, podemos afirmar que o conjunto dessas políticas materializadas nas normatizações e nos referenciais dá contorno à reforma do ensino superior no campo da formação de professores, feita às avessas, à revelia e à margem do movimento dos educadores, das IES, e dos cursos de formação, como parte da reforma mais geral do ensino superior e da reforma do Estado, desencadeada pelo atual governo.

No que tange às concepções de formação, assistimos ao retorno da concepção tecnicista do educador (neotecnicismo), tal como anunciado por Freitas (1992), com ênfase nos aspectos pragmatistas da formação. A opção por esse modelo de formação atende aos princípios de flexibilidade, eficiência e produtividade dos sistemas de ensino, negando toda a trajetória do movimento dos educadores em sua luta pela melhoria das condições de sua formação profissional, retirando das faculdades/centros de educação a experiência construída historicamente de formação de professores e de produção de conhecimento na área educacional, sobre a escola, o ensino e o trabalho pedagógico em suas múltiplas dimensões.

Portanto, reafirmar as formulações e concepções históricas do movimento passa a ser uma exigência, para os educadores, na discussão das diretrizes curriculares, nas reformulações curriculares e na organização de novos cursos de formação, de forma que possam constituir-se em norte para as ações no campo da formação dos profissionais da educação. 


\title{
A concepção de formação e a base comum nacional
}

A questão da formação do educador sempre foi examinada pela Anfope de forma contextualizada, por entendê-la

\begin{abstract}
inserida na crise educacional brasileira, que por sua vez constitui uma das facetas de uma problemática mais ampla, expressão das condições econômicas, políticas e sociais que configuram uma sociedade profundamente desigual e injusta que vem esmagando a grande maioria da população e relegando-a a uma situação de exploração e miséria. ${ }^{13}$
\end{abstract}

Há hoje uma consciência generalizada de que a formação de professores é um desafio relacionado com o futuro da educação básica, esta, por sua vez, intimamente vinculada com o futuro de nosso povo e a formação de nossas crianças, jovens e adultos. No entanto, as perspectivas de que essa formação ocorra em bases teoricamente sólidas e fundada nos princípios de uma formação de qualidade e relevância social são cada vez mais remotas, no quadro das políticas educacionais implementadas.

A redução dos recursos públicos para a educação pública, o asfixiamento das universidades públicas, a trágica realidade da escola pública - exposta no documento "Retrato da Escola"14, elaborado pela CNTE - vão evidenciando a impossibilidade de resolução desses problemas nos marcos das relações sociais vigentes. A consciência dessa situação por parte dos educadores exige o desvelamento dos reais fundamentos das propostas de formação de professores em curso em nosso país. Assumir com radicalidade as propostas de profissionalização do magistério, dando-lhes o conteúdo que o movimento dos educadores vem construindo ao longo de sua história, este parece ser o desafio atual.

Nesse contexto, é importante explicitar as contradições presentes nas propostas oficiais, aprofundando a discussão de uma política nacional global de formação dos profissionais para a educação. A luta pela igualdade das condições de formação, que se configura como um direito dos sujeitos e um dever do Estado, está em contradição com as - e em oposição frontal às - políticas atuais que propugnam a igualdade de oportunidades ou eqüidade, que se configura como um dever dos sujeitos e um direito do Estado. 
A igualdade das condições de formação supõe fundamentalmente a possibilidade de estudos em cursos e instituições que recusem a fragmentação e as dicotomias entre a formação de professores e os demais profissionais da educação, rejeitando, portanto, as propostas atuais que reforçam o aligeiramento no conteúdo e no tempo da formação. A definição das bases da formação no contexto de uma política global de formação ganha, nesse contexto, importância crucial, como forma de expressar as diferentes concepções de educação e de educador que estão em debate nas circunstâncias atuais. Esta tem sido a preocupação central da Anfope na última década, período em que as reformas neoliberais causaram impacto de forma mais direta na educação, na escola pública e na formação de professores.

$\mathrm{Na}$ definição dessa política devem se articular a formação inicial com a formação continuada e as condições de trabalho e salários dignos e justos, entendendo que a "implantação de uma política de formação inicial e continuada deve colocar em questão a responsabilidade dos estados em relação à mesma, bem como o financiamento para sua implementação" "15. Paralelamente e em estreita dependência, entende-se que a profissionalização do educador supõe a valorização dos profissionais, o que requer condições adequadas para o exercício da profissão, carreira e o desenvolvimento de uma política salarial unificada. Entendese ainda a formação continuada como um direito dos professores e dever do Estado e das agências contratantes.

Na perspectiva de uma educação crítica e transformadora, deve-se também reafirmar a concepção sócio-histórica de educador, definida pelo movimento dos educadores e defendida pela Anfope, concepção de formação do profissional de caráter amplo, com pleno domínio e compreensão da realidade de seu tempo, com a consciência crítica que lhe permita interferir e transformar as condições da escola, da educação e da sociedade, um

educador que, enquanto profissional do ensino (...) tem a docência como base da sua identidade profissional, domina o conhecimento específico de sua área, articulado ao conhecimento pedagógico, em uma perspectiva de totalidade do conhecimento socialmente produzido que lhe permita perceber as relações existentes entre as atividades educacionais e a totalidade das relações sociais, econômicas, políticas e culturais em que o processo educacional ocorre, sendo capaz de atuar como agente de transformação da realidade em que se insere. (Conarcfe 1989) 
É essa concepção, reafirmada e aprimorada ao longo da trajetória de construção coletiva dos educadores, que tem orientado estudos que foram dando forma e conteúdo às idéias, proposições e propostas de reestruturação curricular, particularmente nos cursos de pedagogia de numerosas instituições em nosso país, ${ }^{16}$ em resposta aos ideais dos educadores na luta pela democratização da escola, da educação, pela valorização e profissionalização do magistério.

A produção teórica do movimento dos educadores evidencia concepções avançadas sobre a formação do educador, não apenas por destacar seu caráter sócio-histórico, mas principalmente por contribuir com a construção de propostas de superação das dicotomias presentes na formação de professores e dos especialistas, entre bacharelados e licenciaturas e entre pedagogia e demais licenciaturas. Esta é uma exigência dada pela democratização das relações entre os sujeitos no trabalho pedagógico e na construção de novos projetos coletivos. A explicitação da dimensão social da educação e da escola torna evidência a estreita vinculação entre a forma de organização da escola na sociedade capitalista e a formação do educador, fato que coloca em oposição os projetos conservadores da sociedade atual e o projeto histórico que busca a superação do capitalismo e anuncia a concepção de futuro da humanidade que pretendemos.

Essas concepções encontraram sua forma mais elevada na elaboração da base comum nacional que vem sendo construída cotidiana e coletivamente nas propostas concretas de organização curricular nas diferentes IES de nosso país, articulando a unidade dos educadores em torno de princípios norteadores da formação.

O conteúdo da formulação da base comum nacional é um instrumento de luta e resistência contra a degradação da profissão do magistério, permitindo a organização e reivindicação de políticas de profissionalização que garantam a igualdade de condições de formação. É ainda um elemento unificador da profissão, ao defender que a docência é a base da formação de todos os profissionais da educação, pois permite assumir com radicalidade, ainda hoje, nas condições postas para a formação de professores, a formulação de Saviani (1982): formar o professor e o especialista no educador.

A idéia de base comum nacional, que se originou no I Encontro Nacional, realizado em 1983, em contraposição à idéia de formação do pedagogo generalista, contém um conjunto de princípios norteadores 
que vêm sendo construídos, retomados, ressignificados na trajetória da entidade e na construção prática das transformações curriculares que se desenvolvem nas diferentes IES. Princípios que são orientadores do exame, da análise e das propostas de estrutura e organização curricular e institucional dos cursos de formação de profissionais da educação, os quais podem ser assim sistematizados:

a) sólida formação teórica e interdisciplinar sobre o fenômeno educacional e seus fundamentos históricos, políticos e sociais, bem como o domínio dos conteúdos específicos a serem transmitidos pela escola, que permita a apropriação do processo de trabalho pedagógico;

b) unidade teoria/prática que implica assumir uma postura em relação à produção de conhecimento que impregne a organização curricular dos cursos; tomar o trabalho como princípio educativo na formação profissional, revendo-se os estágios e sua relação com a rede pública e a forma de organização do trabalho docente na escola; e ênfase na pesquisa como meio de produção de conhecimento e intervenção na prática social;

c) gestão democrática como instrumento de luta contra a gestão autoritária na escola, entendida como superação do conhecimento de administração enquanto técnica, a fim de apreender o significado social das relações de poder que se reproduzem no cotidiano da escola, nas relações entre os profissionais, entre estes e os alunos, assim como na concepção e elaboração dos conteúdos curriculares;

d) compromisso social e político do profissional da educação, com ênfase na concepção sócio-histórica de educador, estimulando a análise política da educação e das lutas históricas dos profissionais professores articuladas com os movimentos sociais;

e) trabalho coletivo e interdisciplinar entre alunos e entre professores como eixo norteador do trabalho docente na universidade e da redefinição da organização curricular; a vivência e a significação dessa forma de trabalho e da produção de conhecimento permitem a apreensão dos elementos do trabalho pedagógico na escola e das formas de construção do projeto pedagógico-curricular de responsabilidade do coletivo escolar;

f) formação inicial articulada à formação continuada, assegurando solidez teórico-prática na formação inicial e diálogo permanente entre 
o locus de formação inicial e o mundo do trabalho, por intermédio de programas e projetos de educação continuada, correspondendo à concepção de uma formação em redes de conhecimento e saberes, incluindo os programas de pós-graduação (Anfope 1998) ${ }^{17}$.

Esses princípios orientadores, construídos e reafirmados a cada Encontro Nacional, configuram-se também instrumento de análise e discussão das políticas atuais no campo da formação de professores. Eles têm orientado a atuação dos educadores nas últimas décadas e nos últimos dois anos vêm referenciando o movimento e as discussões, em nível nacional, das diretrizes curriculares para os cursos de formação dos profissionais da educação.

\section{As diretrizes curriculares e a escola única de formação: Uma proposta em construção}

O processo de elaboração das diretrizes curriculares para os cursos de graduação, desencadeado pelo MEC e pelo CNE em 1997, insere-se no processo de "ajuste" das universidades às novas exigências dos organismos internacionais, em particular do Banco Mundial e do $\mathrm{FMI},{ }^{18}$ e visa adequar a formação de profissionais ao atendimento das demandas de um mercado globalizado. No campo da formação de professores, o processo de elaboração das diretrizes expressa as contradições presentes nas discussões atuais, trazendo à tona os dilemas e as dicotomias no processo de formação: professor x generalista, professor $x$ especialista e especialista $x$ generalista $^{19}$.

Coerente com as formulações históricas da entidade, a Anfope reafirma em seu documento que propõe as diretrizes para os cursos de formação dos profissionais da educação, as universidades e suas faculdades/ centros de educação como o locus privilegiado da formação dos profissionais da educação para atuação na educação básica e no Ensino Superior. Nessa discussão, vem dando ênfase a duas questões fundamentais: a) a necessidade de repensar as estruturas das faculdades/centros de educação e a organização dos cursos de formação em seu interior, e b) a necessidade de superar a fragmentação entre as habilitações no curso de pedagogia e a dicotomia entre a formação dos pedagogos e dos demais licenciados.

A decisão de formular diretrizes exclusivamente para formação de professores ${ }^{20}$, em separado da elaboração das diretrizes para o curso de 
pedagogia, retirando do debate a formação dos profissionais da educação não é uma questão menor; pelo contrário, é uma questão do conteúdo da formação, que envolve concepções de escola, educação, sociedade e educador que assumimos e que fundamentam e informam as propostas de organização curricular e institucional no campo da formação.

Entendidas como elementos norteadores gerais das organizações curriculares, por conta da flexibilidade que propugnam, as diretrizes podem apontar e reforçar o aligeiramento, colocando em risco a sólida formação teórica no campo de conhecimento específico, necessária para a formação científica e crítica dos profissionais. Contraditoriamente, abrem a possibilidade da construção de novas alternativas no campo institucional e acadêmico nas instituições de ensino superior. No meio dessas contradições, cabe ao movimento dos educadores dar conteúdo e forma a esse debate, redirecionando-o para o resgate das concepções presentes hoje nas diretrizes para o curso de pedagogia e em grande parte dos cursos de pedagogia, socializando-as para o conjunto dos cursos de formação.

As políticas atuais, que reforçam o aligeiramento e o caráter pragmático e conteudista da formação e da profissionalização do magistério, exigem a socialização de propostas de organização curricular para os cursos de formação dos profissionais da educação. É com esse objetivo que a Anfope resgata a idéia de escola única de formação, formulada por essa mesma associação em $1992^{21}$ e aprofundada no IX Encontro Nacional, em 98.

Essa proposta de escola única de formação - única porque o conteúdo da formação é articulado e comum a todos os profissionais da educação para todos os níveis (e não como modelo único de formação ou como local específico de formação) - é uma das muitas possibilidades na direção de concretizar alternativas às formas atuais de estrutura dos cursos de formação. Acreditamos ser necessário continuar defendendo a multiplicidade de experiências em termos de organização curricular dos cursos de formação, que sejam acompanhadas em seu desenvolvimento, socializadas e debatidas amplamente pela comunidade da área. Esse parece ser um bom caminho, em oposição ao modelo único de formação, para a construção de caminhos alternativos à formação de professores/ profissionais da educação, com vistas ao aprimoramento da educação e da escola públicas em nosso país.

Do ponto de vista da Anfope, deve ser entendida como uma das propostas possíveis, resultante de um esforço coletivo, e proposta gera- 
dora de reflexões a serem ampliadas. Como já se apontava em 1992, ela traz, em si, elementos teóricos de grande complexidade e busca dar forma e estrutura ao conteúdo acumulado nas reflexões e experiências coletivas. No entanto, entendemos também que, como uma das propostas possíveis, deve ser estudada tanto na perspectiva de uma proposta futura, quanto na perspectiva de uma proposta em construção.

Nas circunstâncias atuais, em que a proposta dos Institutos Superiores de Educação e do Curso Normal Superior marca uma reforma universitária imposta no campo da formação, é possível e mesmo desejável que diferentes propostas de organização curricular, oriundas de iniciativas individuais, de entidades ou instituições, possam ser amplamente divulgadas e socializadas, para que possam constituir-se em referência para o movimento dos educadores que, em cada instituição, poderá construir caminhos alternativos fundados em concepções de educação, educador e sociedade explícitas e presentes nos projetos pedagógicos dos cursos de formação.

\section{O papel das faculdades e dos centros de educação}

Apesar das deliberações e pareceres que negam a priorização dessas instituições como responsáveis pela formação, entendemos que as universidades e suas faculdades/centros de educação constituem-se no locus privilegiado da formação dos profissionais da educação para atuação na educação básica e no ensino superior. Entretanto, as exigências cada vez mais presentes no campo da formação de professores nos colocam também o desafio de repensar as estruturas atuais das faculdades/centros de educação e a organização dos cursos de formação em seu interior, no sentido de superar a fragmentação entre as habilitações no curso de pedagogia e a dicotomia entre a formação dos pedagogos e dos demais licenciados, considerando-se a docência como a base da formação e da identidade profissional de todos os profissionais da educação.

As áreas e os âmbitos de atuação das faculdades/centros/departamentos de educação inserem-se na formação inicial dos profissionais da educação, formação em nível de pós-graduação lato e stricto senso e formação continuada, presencial e a distância.

Na proposta de escola única, as várias instâncias formadoras são articuladas na faculdade/centro/departamento de educação e concebidas 
como programas articulados e supradepartamentais, sendo cada um dos programas, unidades com responsabilidades de pesquisa, ensino e extensão, articuladas em uma coordenação colegiada.

Mesmo considerando a universidade como o locus privilegiado para a formação de professores, não se pode desconhecer, no entanto, a existência de dificuldades oriundas da estrutura atual que devem ser encaradas como inibidoras e limitadoras de passos mais avançados na direção de novas estruturas de formação. Entre essas dificuldades, apontamos algumas que já em 1992 foram destacadas pela Anfope e que se mantêm, na atualidade, em grande parte das instituições: restrições orçamentárias que impedem a busca de alternativas criadoras no sentido de romper as barreiras das diferentes unidades da universidade; distanciamento entre faculdades/centros de educação e os institutos, tanto de ordem físico-espacial quanto de objetivos, interesses e intenções no campo da pesquisa, do ensino e da extensão; falta de recursos humanos para dar conta das responsabilidades atribuídas às faculdades de educação em relação às licenciaturas; fragmentação e departamentalização nas próprias faculdades de educação (que ainda não foram superadas, apesar das possibilidades da LDB); resistências em assumir co-responsabilidades, levando a uma luta por poder, prestígio e na busca de identidade entre faculdades e institutos; desprestígio e desvalorização da profissão do magistério, o que leva os estudantes a optar pelo bacharelado, e só depois pela licenciatura, impossibilitando a criação de cursos de formação de professores com propostas pedagógicas próprias; dificuldades em romper a atual estrutura e a carga didática das disciplinas das licenciaturas, limitadas às psicologias, fundamentos, didática e práticas de ensino, com algumas inovações no campo de disciplinas de instrumentalização e projetos.

Se essas limitações são impeditivas de novas construções curriculares, todos os esforços deveriam ser direcionados para superá-las. Somente sua superação pode auxiliar a enfrentar a tentativa de retirada dos cursos de formação de seu interior ou a criação de novas unidades acadêmicas - Institutos Superiores de Educação - ou outras instituições, caminhos que certamente aprofundarão e perpetuarão os problemas já existentes.

Experiências em curso em várias instituições apontam para a superação dos departamentos como forma organizacional do ensino e da pesquisa no interior das faculdades de educação, com a criação de núcleos, áreas temáticas ou outras formas de organização, que alteram significativamente a forma de produção de conhecimento no interior dos cursos e programas das unidades universitárias. Repensar tais estrutu- 
ras também pode ser um caminho interessante para a construção de novas proposições para a formação de professores.

\section{Os cursos e programas de formação de professores}

As faculdades ou centros de educação, em estreita articulação com os institutos/faculdades/departamentos das áreas específicas e mantendo vinculação orgânica com os sistemas públicos de ensino, são responsáveis, no interior das IES, pela construção do projeto pedagógico próprio dos cursos e programas de formação dos profissionais da educação. Já existem numerosas experiências nesse sentido, especialmente nas instituições que experienciam os Fóruns de Licenciaturas como forma de articular e integrar toda a formação de professores da instituição.

A proposta em discussão prevê que os cursos atualmente existentes para atender à formação inicial para a educação básica - educação infantil, Ensino Fundamental e Ensino Médio -, à formação continuada e à formação de professores para os cursos técnicos/profissionalizantes e superior desdobrem-se em programas de formação de professores, com as seguintes características:

Programa de formação de profissionais para educação básica curso de pedagogia: docência das séries iniciais do ensino fundamental - $1^{\text {a }}$ a $4^{\underline{a}}$ série e educação infantil, ou outras modalidades, contemplando as dimensões de gestão e organização do trabalho pedagógico escolar e pesquisa, de plena responsabilidade das faculdades/centros/departamentos de educação;

Programa de formação de profissionais para a educação básica: cursos de licenciatura para a docência de $5^{\mathrm{a}}$ a $8^{\mathrm{a}}$ série, Ensino Médio, em estreita vinculação e interface com os institutos das áreas específicas;

Programa de formação de profissionais da educação para gestão e coordenação pedagógicas na escola básica (esse programa, presente no curso de pedagogia, seria articulado aos cursos/programas de formação de professores das áreas específicas e aberto a todos os estudantes, que poderiam cursá-lo concomitantemente ou após a formação específica, dependendo da estrutura organizacional da instituição formadora);

Programa de formação pedagógica para portadores de diploma de Ensino Superior, considerando-se a necessária revisão da Resolução 
02/97 de modo a ampliar o mínimo necessário no que tange aos conhecimentos das áreas específicas e pedagógico-didáticos;

Programas de formação continuada, para profissionais da educação básica;

Programas de educação a distância;

Programas de formação em educação sindical, educação especial, educação de jovens e adultos, produção de material didático, novas linguagens, multimídia, entre muitas outras modalidades que abranjam o campo de atuação do pedagogo, como ênfases nos demais cursos ou articulados em outra forma, dependendo da instituição;

Programas de pós-graduação stricto e latu sensu em educação.

Todos esses programas articulam-se entre si, a partir da concepção de base comum nacional. Com essa organização, abre-se a oportunidade para que certas atividades sejam vivenciadas conjuntamente por todos os alunos dos programas, inclusive no nível dos conteúdos formativos das áreas de fundamentos e outros da base comum nacional - como os relativos à iniciação à pesquisa, práticas pedagógicas, vivências e estágios profissionais, gestão e organização do trabalho pedagógico e do trabalho escolar, por exemplo.

Importante ressaltar também que o corpo docente não é exclusivo de um ou outro programa, mas é altamente desejável que se movimente entre os programas de formação inicial e a pós-graduação.

Em cada instituição, as faculdades/centros/departamentos de educação, em parceria com os institutos/centros/departamentos das áreas específicas, poderão constituir colegiado próprio, com a participação de professores e estudantes, buscando incorporar professores da rede pública e entidades sindicais de professores. Esse colegiado é responsável pela definição da política global de formação nos cursos e programas de formação dos profissionais da educação. Os atuais Fóruns de Licenciaturas e Comissões de Graduação dos cursos de pedagogia, onde existirem, poderiam constituir-se conjuntamente como esse colegiado, responsáveis pela definição e pela articulação dessa política, buscando articulação também com as Comissões de Pós-graduação, no que diz respeito à pesquisa e à articulação da formação de profissionais para o Ensino Superior.

Esse espaço institucional de formação - tenha a denominação de escola única ou qualquer outra -, desde que incorpore os conteúdos da formação dos atuais cursos de pedagogia à nova estrutura curricular e 
organizacional, abre perspectivas inovadoras para a formação de professores, no interior das IES, baseando-se nas experiências atualmente existentes - consolidadas e em desenvolvimento - e constituindo-se como o novo que avança para formas superiores de organização.

As alternativas que se desenham no cenário educacional postas pelo quadro das atuais políticas para a formação de professores desafiam-nos a pensar propostas concretas que possam consolidar a base comum nacional em uma perspectiva de saídas alternativas à atual estrutura dos cursos de formação, em oposição às propostas atuais dos Institutos Superiores de Educação e do Curso Normal Superior.

Pensar essas alternativas é colocar em movimento as concepções e práticas que orientam o pensamento mais avançado no campo da formação de professores, garantindo as atuais formas e aprimorando-as na busca por uma educação com bases sólidas voltada para a formação humana.

NOTA: Ao terminar este artigo, tomamos conhecimento do Decreto Presidencial $\mathrm{n}^{\circ} 3.276$ de 6 de dezembro de 1999, regulamentando a formação de professores para a educação básica, e estabelecendo que a formação de professores para as séries iniciais e educação infantil se dará exclusivamente nos Cursos Normais Superiores. Assim, de forma autoritária, violenta, é imposta pelo governo e pelo MEC a reforma no campo da formação. Vencidos e derrotados na discussão aberta e democrática e pela construção teórica da área, impõe pela força da lei a discussão vencida. O medo da derrota, em virtude das pressões dos setores privatistas e dos compromissos com os ajustes das agendas internacionais, atropelou o próprio $\mathrm{CNE}$, que vinha discutindo a questão.

Só o tempo e a realidade podem confirmar ou rejeitar a validade de certas idéias. Nada nem ninguém mais.

\section{Notas}

1. Dentre essas medidas anteriores à LDB, destacamos a Portaria das Licenciaturas (Esquema I), posteriormente transformada em Resolução 02/97 aprovada pelo CNE, o PL 370 da autonomia universitária, Fundo de Manutenção e Desenvolvimento do Ensino Fundamental e Valorização do Magistério (Fundef), escolha de dirigentes universitários, Parâmetros Curriculares Nacionais, Sistema de Avaliação da Educação Básica, Exame Nacional de Cursos, entre outras. 
2. Cf. IV Encontro Nacional da Comissão Nacional de Reformulação dos Cursos de Formação do Educador (Conarcfe) 1989.

3. Cf. Anfope 1994, p. 28.

4. Cf. Documento "Construindo uma política nacional global de formação dos profissionais da educação", Anfope, out. de 1997.

5. Esse curso, pensado inicialmente na LDB como parte integrante dos Institutos Superiores de Educação, recebeu tratamento diferenciado pelo CNE quando a minuta de Resolução foi devolvida ao Conselho pelo ministro, com a recomendação de que a sua criação pudesse estar separada da criação dos ISE, podendo, portanto, existir em qualquer instituição de ensino superior, ou seja, nas universidades, já que, pelo Parecer 115/99, as faculdades integradas e as faculdades isoladas com cursos de licenciaturas deverão se transformar em Institutos Superiores de Educação.

6. Documento distribuído às comissões de especialistas das diferentes áreas encarregadas de elaborar as diretrizes para as licenciaturas. Guiomar N. Mello, "Formação inicial de professores para a educação básica: Uma (re)visão radical (versão preliminar para discussão interna)". São Paulo, out./nov. 99 (Mimeo).

7. Veja-se a proliferação de cursos de formação de professores em 1.600 horas, com aval dos poderes públicos estaduais.

8. Boletim Anfope no 8, abril 99.

9. Tendo perdido na discussão democrática e aberta com a comunidade da área no processo de elaboração das diretrizes curriculares, o CNE e o MEC tentam impor essa concepção de maneira arbitrária e autoritária, como forma de regulamentar a nova instituição de formação de professores. Infelizmente, encontram guarida em elaborações teóricas de educadores que, talvez de forma desavisada, sob o manto do novo, apresentam idéias que reforçam as políticas neoliberais para a escola pública. Essas idéias estão presentes na produção teórica de alguns estudiosos da área da Didática. Cf. Libâneo e Pimenta 1999 (voto em separado).

10. Estudos recentes na área da administração e supervisão educacional reafirmam a docência como base da formação desses profissionais. Ver especialmente Ferreira 1999.

11. A concepção que orienta a separação da formação de professores da formação dos especialistas manifesta no Parecer 970 da CES e nas propostas atuais é a mesma - guardadas as devidas especificidades e nomenclaturas - que orientou, na década de 1970, a concepção de Valnir Chagas, deslocando a formação dos especialistas para a pós-graduação e deixando o curso de pedagogia exclusivamente para formação de professores.

12. Para recuperar a história real de constituição dos cursos de pedagogia, é preciso que nos remetamos também às experiências dos cursos nas diversas IES, reconhecidos como experiências inovadoras no campo da formação. A 
sua história e as reformulações ocorridas nos anos 80 e 90 confundem-se, de forma positiva e significativa, com as lutas do movimento dos educadores pela sólida formação dos profissionais da educação, entendidos aqui os pedagogos e os licenciados, pela democratização da sociedade e pela valorização da educação e da escola públicas.

13. Cf. Anfope, Documento Final VI Encontro Nacional, Belo Horizonte, 1992.

14. Documento-pesquisa da Confederação Nacional dos Trabalhadores da Educação. Entregue ao MEC em 6/11/1999, na Marcha em defesa da escola e da educação públicas.

15. Ver Anfope Regional Sudeste/Estadual RJ, Textos-base 1998.

16. As proposições e os princípios da Anfope e o reconhecimento à contribuição que a entidade e os educadores vêm dando a essa temática podem ser constatados pela referência a ela no documento dos Pró-Reitores de Graduação, de maio de 1996.

17. Cf. Anfope, Documento Final IX Encontro Nacional, Campinas, 1998.

18. O trabalho de Celi Z Taffarel, "Diretrizes curriculares e plano nacional de graduação: Do ataque às consciências ao amoldamento subjetivo", Recife, 1999, mimeo, apresentado no IV Encontro Nacional de Formação dos Profissionais da Educação, traz uma análise detalhada sobre a inserção do processo de elaboração das diretrizes curriculares no quadro das novas demandas do processo de globalização.

19. O próprio MEC constituiu a Comissão de Especialistas de Pedagogia e somente tempos depois constituiu o GT Licenciaturas, separado dos bacharelados.

20. Cf. Boletim Anfope no 11, agosto 1999.

21. Essa proposta surge das contribuições da professora Marlene Ribeiro, posteriormente detalhadas em seu artigo "Formação unificada do profissional de ensino: Uma proposta da Faculdade de Educação da Universidade do Amazonas". Em Aberto nํ 54, 1992.

\section{The reform of superior teaching in the field of professionals ubbringing of basic education: The educational policies and the teachers movement}

ABSTRACT: This work presents the discussion that have oriented the debate about the formation of educational professionals, recuperating the trajectory of the movement of the educators in the struggle for transformation and professionalization of teaching as represented actually by the National Association for the Professional Educators Formation (Anfope), during the last 20 years. The collective construction of common national base in opposition to the formation 
policies and the proposal of a single school of formation which materializes Anfope's principles for the reorganization of the courses of education professional formation in the universities, have oriented the actual debate of resistence to the official policies that propugnes hastening and fragmentation in the professional teaching formation.

\section{Bibliografia}

AGUIAR, Márcia Ângela. "Institutos Superiores de Educação na nova LDB". In: BRZEZINSKI, Iria (org.). LDB interpretada: Diversos olhares se entrecruzam. São Paulo: Cortez, 1997.

. "A formação do profissional da educação no contexto da reforma educacional brasileira". In: FERREIRA, Naura S.C. (org.). Supervisão educacional para uma escola de qualidade. São Paulo: Cortez, 1999.

ANFOPE. Documentos Finais dos VI, VII, VIII e IX Encontros Nacionais da Associação Nacional pela Formação dos Profissionais da Educação, 1992, 1994, 1996 e 1998.

BRASIL/PR. Lei no 9.394, de 20/12/1996. Estabelece as diretrizes e bases da educação nacional. Diário Oficial da União. Brasília: Gráfica do Senado, ano CXXXIV, nl. 248, 23/12/96, pp 27833-41.

BRZEZINSKI, Iria. "A formação e a carreira de profissionais da educação na LDB 9.394/96: Possibilidades e perplexidades". In: BRZEZINSKI, Iria (org.). LDB interpretada: Diversos olhares se entrecruzam. São Paulo: Cortez, 1997.

COMISSÃO DE ESPECIALISTAS DE PEDAGOGIA. Diretrizes Curriculares para o Curso de Pedagogia. MEC/SESu, 1999.

COMITÊ PRÓ-REFORMULAÇÃO DOS CURSOS DE FORMAÇÃO DO EDUCADOR. I Encontro, Belo Horizonte, 1983.

CONARCFE. "Documento Final". III Encontro Nacional da Comissão Nacional de Reformulação dos Cursos de Formação dos Educadores. Brasília, 1988 (Coletânea de Documentos).

. "Documento Final". IV Encontro Nacional, Comissão Nacional de Reformulação dos Cursos de Formação do Educador. Belo Horizonte, 1989. 
. "Documento Final". V Encontro Nacional, Comissão Nacional de Reformulação dos Cursos de Formação do Educador. Belo Horizonte, 1990.

FERREIRA, Naura S.C. Supervisão educacional para uma escola de qualidade. São Paulo: Cortez, 1999.

FREITAS, Helena C.L. de. "Plano decenal de educação: Consenso e cooptação". Revista do Sinpeem $\mathrm{n}^{0} 2$. Sindicato dos Profissionais da Educação no Ensino Municipal de São Paulo, fev. 1995.

- O trabalho como princípio articulador na prática de ensino e nos estágios. Campinas: Papirus, 1996.

FREITAS, Luiz C. de. "A questão da interdisciplinaridade: Notas para a reformulação dos cursos de pedagogia". Educação \& Sociedade no 33. São Paulo: Cortez/Autores Associados, 1989.

"Em direção a uma política para a formação de professores". Em Aberto $\mathrm{n}^{\circ}$ 54. Brasília, ano 12, abr./jun. 1992a.

. "Neotecnicismo e formação do educador". In: ALVES, Nilda (org.). Formação de professores, pensar e fazer. São Paulo: Cortez, 1992b.

. "Ensino de $1^{\circ}$ grau: Instrumento de recuperação econômica?". Universidade e Sociedade $\mathrm{n}^{\circ}$ 7. Andes, ano IV, jun. 1994.

. Palestra de abertura do II Encontro da Regional Sul Anfope. Florianópolis, 1998.

GADOTTI, M. "Elementos para a crítica da questão da especificidade da educação". Em Aberto nº 22. Brasília, ano 3, jul./ago. 1984, pp. 21-30.

KUENZER, A. Z. "A formação dos profissionais da educação: Propostas de diretrizes curriculares nacionais. Anped, 1998. (Mimeo.)

LIBÂNEO, J.C. e PIMENTA, Selma G. "Documento Norteador para a Elaboração das Diretrizes Currriculares para os Cursos de Formação de Professores". SESu/MEC. Set. 1999 (voto em separado).

MELLO, Guiomar N. de. "Formação inicial de professores para a educação básica - Uma revisão radical." (documento principal) versão preliminar para discussão interna. Outubro/Novembro de 1999, (Mimeo). 
PINO, I. e GADOTTI, M. "A redefinição do curso de pedagogia: Idéias, diretrizes”. RBEP 63 (144). Brasília, maio/ago. 1979, pp. 59-66.

RASIA, J.M. "Pedagogia e educação ou de como falar sobre o óbvio". Cadernos Cedes ํㅜㄴ. Ano I, 1980.

RIBEIRO, Marlene. "Formação unificada do profissional de ensino: Uma proposta da Faculdade de Educação da Universidade do Amazonas". Em Aberto ${ }^{\circ}$ 54. Brasília, ano 12, abr./jun. 1992.

ROMANELLI, Otaíza de O. História da educação no Brasil. Petrópolis: Vozes, 1978.

SAVIANI, D. Educação: Do senso comum à consciência filosófica. São Paulo; Campinas: Cortez/Autores Associados, 1980.

. "Uma estratégia para a reformulação dos cursos de pedagogia e licenciatura: Formar o especialista e o professor no educador”. Em Aberto nํ 8. Brasília, ano 1, ago. 1982.

TORRES, R.M. "Melhorar a qualidade da educação básica? As estratégias do Banco Mundial". In: DE TOMMASI, L., WARDE, M.J. e HADDAD, S. (orgs.). O Banco Mundial e as políticas educacionais. São Paulo: Cortez, 1996.

\section{Documentos complementares}

ANFOPE. "Posição na audiência pública, convocada pelo CNE, sobre formação dos profissionais da educação. Brasília, 1998, (Mimeo).

. "Diretrizes curriculares para os cursos de formação dos profissionais da educação". Reunião anual da ANPEd, 1998, (Mimeo).

ANFOPE REGIONAL SUL. "Conclusões do Encontro Regional e Estadual." Rio de Janeiro, 1998, (Mimeo).

ANFOPE REGIONAL SUDESTE/ESTADUAL RJ. "Conclusões do Encontro

Regional e Estadual. Rio de Janeiro, 1998, (Mimeo). 